\title{
Research Trends for Improvement of Biotope Area Index
}

\author{
Byeong-Hwa Song ${ }^{1}$ and Sung-Ho Kil ${ }^{2}$ * \\ ${ }^{1}$ Department of Landscape Architecture and Horticultural Science, World Cyber College, Gwangju, Gyeonggido 12771, South Korea \\ ${ }^{2}$ Department of Ecological Landscape Architecture Design, Kangwon National University, Chuncheon 24341, South Korea
}

\begin{abstract}
The Biotope Area Index (BAI) is an indicator applied to the field in various types of spaces such as apartment complexes, business and educational facilities. However, the BAI would be requested for the supplement and improvement reflected by practical approaches. Therefore, this study was conducted through comparative analyses of foreign indexes similar to the BAI and previous studies in order to improve the BAI. The research process consists of reviewing the actual application of the previous BAl, and comparing and analyzing the types and weights of foreign BAls. Seoul Metropolitan Government adopted Germany's biotope index in 2004 and many studies on the assessment of the BAI through simulation or actual projects were carried out. Green spaces on artificial grounds are used similarly in all indexes, but different weights are applied in some areas. Germany gives the weight of 0.7 to green roofs regardless of soil depth, but under the BAI criteria, green roofs with the soil depth of more than $20 \mathrm{~cm}$ are given with the weight of 0.6 , while those with the soil depth of less than $20 \mathrm{~cm}$ are given with the weight of 0.5 . Distinctively, green roofs weights are given differently based on the soil depth of $80 \mathrm{~cm}$ and $10 \mathrm{~cm}$ in Sweden and United States respectively. In United States, bonuses are additionally given to drought tolerant, native plant species, or landscape areas where at least $50 \%$ of annual irrigation needs are met and plant types are further divided into sub-groups. BAI studies have mainly been conducted on spatial types and weights. Establishment of the systematic framework as a environmental planning indicator, consideration of the potentiality as a quantitative indicator, overcoming limitations as a two-dimensional indicator, and enhancement of a functional role of estimation index by tree planting could be necessary for BAI improvements.
\end{abstract}

Keywords: BFF (Biotopflächenfaktor), Environmental Index, GSF (Green Space Factor), SGF (Seattle Green Factor)

\section{Introduction}

Cities in South Korea are densely populated, and the impermeable soil coverage area has continued to increase due to urbanization caused by rapid industrialization (Kim, 2012), which has resulted in a decrease in the soil's ability to absorb water, an increase in the surface area of materials with a low heat capacity such as cement, the destruction of a balanced ecosystem due to a decrease in habitats, flooding in urban areas, urban desertification caused by shrinking green spaces in urban areas, and the destruction of living spaces for people in urban areas (Lee, 2000). Many countries around the world including Korea have implemented a variety of programs to reduce these phenomena.

This study utilized some parts of the doctoral thesis of Song, BH (2016), and was supported by the Forestry Science Technology Development Program (No. 2017043B10-1819-BB01) of the Korea Forest Service (KFS).

Received: February 2, 2018, Revised: February 9, 2018, Accepted: February 26, 2018

First author: Byeong-Hwa Song, E-mail: sbh0805@hanmail.net, ORCID: 0000-0002-7854-1590

*Corresponding author: Sung-Ho Kil, E-mail: sunghokil@kangwon.ac.kr, ORCID: 0000-0001-9388-1852

C 2018 by the Society for People, Plants, and Environment. This is an Open Access article distributed under the terms of the Creative Commons Attribution Non-Commercial License (http://creativecommons.org/licenses/by-nc/4.0/) which permits unrestricted non-commercial use, distribution, and reproduction in any medium, provided the original work is properly cited. 
Among them, the Biotope Area Index (BAI) is similar to a program that requires a certain percentage of landscaping area under the Building Act, but the BAI program suggests 12 weighted types of spaces in order to fully consider the competence of architects or landscape architects depending on regional conditions. In addition, the program can be utilized as an indicator for urban planning and as a means to manage urban environments in establishing basic plans for cities, counties or districts, not just a regulation that stipulates a certain size of land. The Biotope Area Index (BAI) was introduced in Seoul in 2004, and has been applied to urban development projects and those subject to environmental impact assessment. Its guidelines were revised in 2007, and the BAI application criteria for environmental impact assessment were established under the Urban Planning Ordinance of Seoul to strengthen requirements. However, for the past ten years since the enactment of the ordinance, green infrastructure technologies associated with artificial grounds have been remarkably advanced and various products and construction methods suitable for artificial grounds and green roofs have been developed and applied on sites. However, the existing BAI types and weights have not been updated to meet the current technology levels and conditions, which raises the importance of improving the BAI.

In this regard, this study aimed to review earlier studies on improvement in the Biotope Area Index (BAI) and indices used in other countries, and to suggest measures to improve the BAI program.

\section{Methods}

Earlier studies related to the Biotope Area Index (BAI) that were conducted in Korea were reviewed first, and cases in other countries were examined later. The existing BAI (as of 2016) and other cases were compared to suggest ways to improve the BAI used in Korea.

For overseas cases, 3 indices used in 3 cities (Berlin in Germany, Malmö in Sweden, Seattle in the United States) were selected. The three indices were analyzed and compared with Korea's BAI. The selected indices of Germany, Sweden and the United States have been widely used, and they were analyzed based on the guidelines that are available on their homepages. The materials were collected to compare the types, weighted values and actual cases of the indices with those of Korea's BAI types, and thus to identify similarities and differences.

\section{Research Trends on BAl in Korea}

\section{Studies on the application of BAI}

Earlier studies on the Biotope Area Index (BAI) were mostly focused on apartment houses. Some studies suggested criteria (Koo et al., 2007; Kim, 2015) and measures for improvement (Jang et al., 2010; Kim, 2009; Hong, 2005; Yu, 2008; Lee, 2007), and some studies analyzed the BAI (Jang et al., 2012; Son, 2015; Kang, 2009; Hong et al., 2012; Lee, 2010; Kang and Lee, 2014). Out of them, those related to this study were reviewed in detail, and the results were utilized to identify limitations found in the BAI, and suggest measures to improve the index.

Studies on setting BAI criteria for apartment houses did not consider the characteristics of land uses and sizes in Seoul, but uniformly applied the BAI.

Out of those that researched problems and measures for improvement in the BAI, Hong (2005) pointed out the applicability of the BAI and consequent issues, and suggested directions for improving the BAI and considerations for applying the BAI based on the identified problems. Although school playgrounds are created on natural grounds, they are mostly covered with materials such as soil cement. For this reason, the weight of such playgrounds is only 0.3 , and thus they fail to meet the BAI criteria. Since the entire area of schools needs to be permeably paved, it has been recommended 
to increase their weight. In addition, if the BAI is applied to certain districts for redevelopment or reconstruction projects in a biased way, it is difficult to maintain connectivity between areas and green areas.

In another study, the types of the BAI and their weights in Korea were simulated and measures to improve the BAI were suggested based on the results of simulations (Jang et al., 2012). In the study, the BAI distribution of 12 apartment houses built in housing site development sites in the Seoul metropolitan areas was researched, and paved areas accounted for the largest part, while the ratio of those that have an ecological function was very low. The contribution of improvement needs to be estimated in consideration of its correlation between the cost of construction per unit area and the level of contribution of the improved BAI.

Jang et al. (2012) suggested adding a vegetated area as a new type to the BAI in order to improve criteria for the surface types of the existing BAI. In the study, other indices used overseas as an indicator for environmental plans including the Biotopflächenfaktor (BFF) of Berlin, the Green Space Factor (GSF) of Malmö and the Seattle Green Factor (SGF) of Seattle were analyzed, and measures for improvement were suggested based on the analysis results. The types of grounds, paved spaces, paved spaces, three-dimensional greening, vegetation and water spaces in landscaping areas, and their weights were compared with cases in Korea, but still the results did not meet situations in Korea.

In addition, Jang et al. (2010) conducted a study on the improvement in the biotope area index through an assessment on apartment houses after creating outdoor spaces, and, in the study, the following four cases were examined: a review of self-assessment and certification reports on landscaping in outdoor spaces in apartment houses; an analysis of the status of BAI certification; a review of areas in the BAI to be revised by re-calculating planning indices after the completion of construction; and a comparison analysis of calculated BAI values. In the study, several problems by the type of space were pointed out as follows: first, changes in the BAI due to advancement in methods of crack permeable pavement; second, insufficient criteria for the wallgreening type; and third, the low utilization and maintenance of water spaces. In order to promote the use of the BAI, criteria should be strengthened for methods of crack permeable pavement that has accounted for the largest part of the recently paved areas, and performance between methods of permeability coefficient should be differentiated.

In another study, the cost-effectiveness of the application of the BAI was analyzed to verify the validity of introducing the BAI to local governments (Son, 2015). In the study, among 5 projects for improving residential environments in old downtown areas, 3 districts with a different project size and other projects that are the same type but have a different area size were analyzed. The BAI of the projects was analyzed by the type of project, and it was found that the cost of redevelopment projects was the largest, and that, considering the size of apartment houses, the cost of applying the BAI was of little importance. The BAI of the projects was also analyzed by the size of project, the cost of applying the BAI to small-scale projects was low, but that it was relatively easier to apply it to large-scale projects.

Lee (2011a) focused on the importance of considering the BAI from the planning stage in various types of large-scale development projects that are subject to environmental impact assessment. In the study, the validity and effectiveness of introducing the BAI were analyzed first, and directions and measures to improve the BAI were suggested. Those suggestions were tested and feedbacks were provided. Based on the results, target BAI values were calculated. Seoul started to set the BAI criteria in order to improve their effectiveness in 2004 based on the Biotopflächenfaktor (BFF) used in Berlin, Germany, and has applied them to urban planning. However, in the stage of environmental impact assessment in which there is no detailed drawing available, it is impossible to measure the index, and to apply it to projects other than housing site development projects or urban planning projects, which reduces its effectiveness. To address these issues, the BAI needs to be improved in order to calculate target BAI values even when there is no information available on pavement materials or drawings. In addition, it will be necessary to develop measure to set detailed target BAI values in the stage of 
environmental impact assessment, and detailed plans for applying the index to different types of site.

Studies on measures to improve the index and assessment system pointed out that the index that has been applied only to housing site development projects and some urban development projects can be applied to all project types, and that target values can be set depending on the characteristics of project sites. It was also pointed out that detailed target values can be set for environmental impact assessment.

\section{Studies on the assessment of the BAI}

There are several studies on items for assessing ecological environments: common assessment items on ecological environments for the green building certification program (Kim, 2015; Lee et al., 2011b; Yoon et al., 2011); decentralized rainwater management methods for securing water circulation systems for ecological urban development (Han, 2005); and an analysis of the characteristics of and trends in the land coverage of the outdoor spaces of high-rise buildings from the perspective of the BAI (Hong et al., 2012).

Kim (2015) reviewed the distribution of marks and weights, used as criteria for certifying green buildings and ecological environments both in Korea and overseas including Green Standard for Energy and Environmental Design (G-SEED), Leadership in Energy and Environmental Design (LEED), Building Research Establishment Environmental Assessment Method (BREEAM) and Comprehensive Assessment System of Building Environmental Efficiency (CASBEE) by the type of construction.

Yoon et al. (2011) summarized key changes in the revised criteria for eco-friendly buildings, and it was found that the weights of land usages and ecological environments in certification items and criteria decreased most significantly. In particular, key issues observed in the area of ecological environments were highlighted. As the BAI that was used only to grade the performance of houses was introduced, it became difficult to differentiate them, and there is no item and content on the evaluation of the ecological quality of projects. The study highlighted the importance of adding items that can assess the quality of ecological environments in an objective way, and reflecting eco-friendly planning techniques.

In another study on the characteristics of and trends in the land coverage of 15 high-rise building in Korea (Hong et al., 2012), it was pointed out that the share of green and water surfaces is relatively low, compared to the weight of paved surfaces. The study suggested reducing the area of paved spaces, and use other various methods in outdoor spaces in order to improve the ecological function and the BAI of high-rise buildings.

\section{Biotope Area Indices Used in Other Countries}

\section{Types and Weights of BFF Used in Berlin, Germany}

The BFF (Biotopflächenfaktor) used in Berlin is composed of 9 types. The type that has the highest weight is a surface with vegetation directly connection to soil below, which is similar to the type of green spaces created on natural grounds in the BAI used in Korea, and its weight is 1.0. There are two types that has the next highest weight: a surface with vegetation unconnected to soil below, and a green roof. Both the types are given with the weight of 0.7 (Table 1).

\section{Types and Weights of GSF Used in Malmö}

The GSF (Green Space Factor) used in Malmö was developed based on the BFF used in Berlin, and it is calculated by multiplying the factor assigned to each surface type by its area. Surfaces are divided into various types and their weight ranges from 1 for the type of vegetation on the ground to 0 for the type of sealed surfaces. 
Table 1. Biotope surface area type

\begin{tabular}{|c|c|}
\hline Surface Type & Weighting Factor \\
\hline $\begin{array}{l}\text { Sealed Surface } \\
\text { Impermeable to air and water and has no plant growth } \\
\text { (concrete, asphalt, slabs with a solid subbase) }\end{array}$ & 0.0 \\
\hline $\begin{array}{l}\text { Partially Sealed Surface } \\
\text { Permeable to water and air, but no plant growth } \\
\text { (mosaic paving, slabs with a sand/ gravel subbase) }\end{array}$ & 0.3 \\
\hline $\begin{array}{l}\text { Semi-open Surface } \\
\text { Permeable to water and air, some plant growth } \\
\text { (gravel with grass coverage, wood-block paving, honeycomb brick with grass) }\end{array}$ & 0.5 \\
\hline $\begin{array}{l}\text { Surface with Vegetation Unconnected to Soil Below } \\
\text { On cellar covers or underground garages with less than } 80 \mathrm{~cm} \text { of soil covering }\end{array}$ & 0.5 \\
\hline $\begin{array}{l}\text { Surface with Vegetation Unconnected to Soil Below } \\
\text { No connection to soil below but with more than } 80 \mathrm{~cm} \text { of soil covering }\end{array}$ & 0.7 \\
\hline $\begin{array}{l}\text { Surface with Vegetation Connected to Soil Below } \\
\text { Vegetation connected to soil below, available for development of flora and fauna }\end{array}$ & 1.0 \\
\hline $\begin{array}{l}\text { Rainwater Infiltration per } \mathrm{m}^{2} \text { of Roof Area } \\
\text { Rainwater infiltration for replenishment of groundwater; infiltration over surfaces with existing } \\
\text { vegetation }\end{array}$ & 0.2 \\
\hline $\begin{array}{l}\text { Vertical Greenery up to } 10 \mathrm{~m} \text { in Height } \\
\text { Greenery covering walls and outer walls with no windows; the actual height, up to } 10 \mathrm{~m} \text {, is taken } \\
\text { into account }\end{array}$ & 0.5 \\
\hline $\begin{array}{l}\text { Green Roof } \\
\text { Extensive and intensive coverage of rooftop with greenery }\end{array}$ & 0.7 \\
\hline
\end{tabular}

Note. Reprinted from "Adaption to climate change using green and blue infrastructure. A database of case studies", by Kazmierczak, A. and Carter, J., 2010, p. 82, Manchester, United Kingdom: University of Manchester.

Compared to the BFF used in Berlin, relatively high weights are given to surface types except for the types of paved surfaces, and a new surface type (vegetation) and its value are added. In addition, the GSF aims to establish a green base for improving biodiversity and a healthy process of discharging rainwater and thus to additionally improve the quality of the index. Assessment criteria for water spaces were also established. The GSF applied different weighted values to all the surfaces of buildings that are available for greening including roofs and walls, and added water spaces and certain vegetation types in order to ensure ways to control rainwater runoff, encourage biodiversity and restore natural ecosystems are reflected in designing projects (Table 2).

\section{Types and Weights of SGF used in Seattle}

The SGF (Seattle Green Factor) used in Seattle, the United States gives a high weight to green roofs, vegetated walls and permeable paving in order to make the most of their various advantages and promote the use of technologies associated with the types. Bonus points are also given to landscape areas that are visible to passers-by. The types of the SGF are listed in a worksheet, which includes ground-cover plants, shrubs, permeable paving, green roofs, vegetated walls, artificial waterways, rainwater gardens, drought-tolerant plants and landscape areas.

Each surface type is given with a weight ranging from 0.1 to 0.7 . Types such as green roofs, vegetated walls, permeable paving are given with a high weight in order to promote various interests, while mulch, ground cover, plants or shrubs less 
Table 2. Green Space Factor (GSF) surface type and value, description and example

\begin{tabular}{|c|c|c|c|c|c|}
\hline Surface Type & $\begin{array}{l}\text { Surface Value } \\
\text { (Vi) }\end{array}$ & Description & $\begin{array}{c}\text { Surface } \\
\text { A }\end{array}$ & $\begin{array}{l}\text { Efficient Surface } \\
\qquad(\mathrm{A} \times \mathrm{Vi})\end{array}$ & $\begin{array}{l}\text { Vegetation used } \\
\text { in Case }\end{array}$ \\
\hline $\begin{array}{l}\text { Vegetation on the } \\
\text { ground }\end{array}$ & 1 & Continuous soil layer & 162 & 162 & $\begin{array}{l}\text { Grass, bushes } \\
\text { and trees }\end{array}$ \\
\hline Green walls & 0.7 & $\begin{array}{l}\text { Calculated from the expected green surface } \\
5 \text { years after installation. The system only } \\
\text { gives credit to green walls up to } 10 \text { meters. }\end{array}$ & 75 & 52.5 & $\begin{array}{l}\text { A } 15 \mathrm{~m} \text { long } \\
\text { and } 5 \mathrm{~m} \text { high } \\
\text { green wall }\end{array}$ \\
\hline Extensive green roofs & 0.8 & Thin substrate and vegetation layers & 30 & 24 & Roof of bike shed \\
\hline Open Water Features & 1 & $\begin{array}{l}\text { The water surface should be present at least } \\
\qquad 6 \text { months every year }\end{array}$ & 60 & 60 & $\begin{array}{l}\text { Pond in the } \\
\text { intensive roof } \\
\text { garden section }\end{array}$ \\
\hline $\begin{array}{l}\text { Intensive Green roof } \\
\text { vegetation }<0,8 \mathrm{~m}\end{array}$ & 0.6 & $\begin{array}{l}\text { The depth only includes rootable surfaces. } \\
\text { The depth requirement relates to rootable } \\
\text { volume and excludes any material below the } \\
\text { root protection layer. }\end{array}$ & 143 & 85.8 & $\begin{array}{l}\text { Turf and perennial } \\
\text { ornamental plants }\end{array}$ \\
\hline $\begin{array}{l}\text { Intensive Green roof } \\
\text { vegetation }>0,8 \mathrm{~m}\end{array}$ & 0.8 & $\begin{array}{l}\text { The depth only includes rootable surfaces. } \\
\text { The depth requirement relates to rootable } \\
\text { volume and excludes any material below the } \\
\text { root protection layer. }\end{array}$ & 62 & 49.6 & Bushes and trees \\
\hline Sealed surface & 0 & - & 423 & 0 & $\begin{array}{l}\text { Roof surfaces } \\
\text { excluding bike shed }\end{array}$ \\
\hline $\begin{array}{l}\text { Paved surfaces with } \\
\text { permeable joints }\end{array}$ & 0.2 & $\begin{array}{l}\text { Permeable joints made of sand or other } \\
\text { material. }\end{array}$ & 200 & 40 & Pavers \\
\hline $\begin{array}{l}\text { Semi-permeable hard } \\
\text { surfaces }\end{array}$ & 0.4 & $\begin{array}{l}\text { Includes surfaces such as reinforced grass, } \\
\text { permeable bitumen, sand, gravel or similar. }\end{array}$ & 0 & 0 & Gravel surfaces \\
\hline Tree $\mathrm{dbh}>35 \mathrm{~cm}$ & 0.4 & $\begin{array}{l}\text { Extra credits for trees are calculated on a } \\
\text { maximum surface of } 25 \mathrm{~m}^{2} / \text { tree }\end{array}$ & 125 & 50 & 5 trees \\
\hline $\begin{array}{l}\text { Shrubs or polycorm } \\
\text { trees }>3 \mathrm{~m} \text { high }\end{array}$ & 0.2 & $\begin{array}{l}\text { Extra credits for shrubs and small trees are } \\
\text { calculated on a maximum surface of } 5 \\
\qquad \mathrm{~m}^{2} / \text { tree }\end{array}$ & 40 & 8 & 8 large shrubs \\
\hline Climbers $>2 \mathrm{~m}$ high & 0.2 & $\begin{array}{l}\text { Extra credits for climbers are calculated as } \\
\text { the surface of a } 2 \mathrm{~m} \text { wide climbing plant. }\end{array}$ & 42 & 8.4 & 7 climbers \\
\hline $\begin{array}{l}\text { Storm-water drains to } \\
\text { vegetation }\end{array}$ & 0.1 & $\begin{array}{l}\text { Includes installations such as rain gardens, } \\
\text { swales and filter strips. }\end{array}$ & 76 & 7.6 & $\begin{array}{l}\text { The pavers drain } \\
\text { towards the } \\
\text { vegetation }\end{array}$ \\
\hline $\begin{array}{l}\text { Detention or retention } \\
\text { ponds }\end{array}$ & 0.2 & $\begin{array}{l}\text { Credits are only given if the installation can } \\
\text { handle at least } 20 \mathrm{~L} / \mathrm{m}^{2} \text { drained surface. }\end{array}$ & 130 & 26 & $\begin{array}{l}\text { Water from the } \\
\text { roof is collected } \\
\text { in the pond }\end{array}$ \\
\hline
\end{tabular}

Note. Reprinted from "A Critical Analysis of the Biotope-Focused Planning Tools: Green Space Factor", by Emilsson. T., Persson, J., and Mattsson, J.E., 2013, Department of Landscape management, Design and Construction, Swedish University of Agricultural Sciences. Department series, 28, pp. 34-37.

than $60 \mathrm{~cm}$ tall are given with a low weight (0.2). Mulch, ground cover or plants more than $60 \mathrm{~cm}$ tall are given with a very high weight (0.7). Bonuses are given to landscape areas visible to passers-by and drought-tolerant plants, and another extra bonus (0.1) is given to improve landscaping functions and encourage to use less water.

The SGF is composed of 7 landscape types and 1 bonus type, and landscape types are weighted specifically. Compared 
Table 3. Seattle Green Factor (SGF) surface type and factor

\begin{tabular}{|c|c|c|c|}
\hline Surface Type & Landscape Elements & Units & Factor \\
\hline \multirow{3}{*}{ A. Landscape areas } & 1. Soil depth of less than $24^{\prime \prime}$ & $\mathrm{sq} f \mathrm{ft}\left(\mathrm{ft}^{2}\right)$ & 0.1 \\
\hline & 2. Soil depth of $24^{\prime \prime}$ or greater & $\mathrm{sq} f \mathrm{ft}\left(\mathrm{ft}^{2}\right)$ & 0.6 \\
\hline & 3. Bioretention facilities & $\mathrm{sq} \mathrm{ft}\left(\mathrm{ft}^{2}\right)$ & 1.0 \\
\hline \multirow{7}{*}{$\begin{array}{l}\text { B. Planting Planting } \\
\text { (Credit for plants in } \\
\text { landscape areas from } \\
\text { Section A) }\end{array}$} & 1. Mulch, Ground cover, or Plants less than $2^{\prime \prime}$ tall at maturity & $\operatorname{sq} \mathrm{ft}\left(\mathrm{ft}^{2}\right)$ & 0.1 \\
\hline & $\begin{array}{l}\text { 2. Shrubs or perennials } 2^{\prime}+\text { at maturity calculated at } 12 \mathrm{ft}^{2} \text { per plant } \\
\text { (typically planted no closer than } 18^{\prime \prime} \text { on center) }\end{array}$ & $18\left(\mathrm{ft}^{2}\right) /$ per tree & 0.3 \\
\hline & $\begin{array}{l}\text { 3. Tree canopy for "small trees" or equivalent } \\
\text { (canopy spread for } 8 \text { ' to } 15 \text { ') - calculated at } 75 \mathrm{ft}^{2} \text { per tree }\end{array}$ & $75\left(\mathrm{ft}^{2}\right) /$ per tree & 0.3 \\
\hline & $\begin{array}{l}\text { 4. Tree canopy for "small/medium trees" or equivalent } \\
\text { (canopy spread for } 16 \text { ' to } 20 \text { ') - calculated at } 150 \mathrm{ft}^{2} \text { per tree }\end{array}$ & $150\left(\mathrm{ft}^{2}\right) /$ per tree & 0.3 \\
\hline & $\begin{array}{l}\text { 5. Tree canopy for "medium/large trees" or equivalent } \\
\text { (canopy spread for } 21 \text { ' to } 25 \text { ') - calculated at } 250 \mathrm{ft}^{2} \text { per tree }\end{array}$ & $250\left(\mathrm{ft}^{2}\right) /$ per tree & 0.4 \\
\hline & $\begin{array}{l}\text { 6. Tree canopy for "large trees" or equivalent } \\
\text { (canopy spread for } 26 \text { ' to } 30 \text { ') - calculated at } 350 \mathrm{ft} 2 \text { per tree }\end{array}$ & $350\left(\mathrm{ft}^{2}\right) /$ per tree & 0.4 \\
\hline & $\begin{array}{l}\text { 7. Tree canopy for preservation of large existing trees with trunks } 6^{\prime \prime}+\text { in } \\
\text { diameter - calculated at } 20 \mathrm{ft}^{2} \text { per inch diameter }\end{array}$ & $\begin{array}{l}350\left(\mathrm{ft}^{2}\right) / \text { per inch } \\
\text { diameter }\end{array}$ & 0.8 \\
\hline \multirow{2}{*}{ C. Green roofs } & 1. Over at least $2^{\prime \prime}$ and less than $4^{\prime \prime}$ of growth medium & $\mathrm{sq} f \mathrm{ft}\left(\mathrm{ft}^{2}\right)$ & 0.4 \\
\hline & 2. Over at least $4^{\prime \prime}$ of growth medium & $\mathrm{sq} \mathrm{ft}\left(\mathrm{ft}^{2}\right)$ & 0.7 \\
\hline D. Vegetated walls & - & $\mathrm{sq} f \mathrm{ft}\left(\mathrm{ft}^{2}\right)$ & 0.7 \\
\hline E. Approved water features & - & $\mathrm{sq} f \mathrm{ft}\left(\mathrm{ft}^{2}\right)$ & 0.7 \\
\hline \multirow{2}{*}{ F. Permeable paving } & 1. Permeable paving over at least 6 and less than $24^{\prime \prime}$ of soil or gravel & $\mathrm{sq} f \mathrm{ft}\left(\mathrm{ft}^{2}\right)$ & 0.2 \\
\hline & 2. Permeable paving over at least $24^{\prime \prime}$ of soil or gravel & $\mathrm{sq} f \mathrm{ft}\left(\mathrm{ft}^{2}\right)$ & 0.5 \\
\hline G. Structural soil system & - & $\operatorname{sq} \mathrm{ft}\left(\mathrm{ft}^{2}\right)$ & 0.2 \\
\hline \multirow{4}{*}{ H. Bonuses } & 1. Drought-tolerant or native plant species & $\mathrm{sq} f \mathrm{ft}\left(\mathrm{ft}^{2}\right)$ & 0.1 \\
\hline & $\begin{array}{l}\text { 2. Landscape areas where at least } 50 \% \text { of annual irrigation needs are met } \\
\text { through the use of harvested rainwater }\end{array}$ & $\mathrm{sq} f \mathrm{ft}\left(\mathrm{ft}^{2}\right)$ & 0.2 \\
\hline & $\begin{array}{l}\text { 3. Landscape visible to passersby from adjacent public right of way or } \\
\text { public open spaces }\end{array}$ & $\mathrm{sq} f \mathrm{ft}\left(\mathrm{ft}^{2}\right)$ & 0.1 \\
\hline & 4. Landscaping in food cultivation & $\mathrm{sq} f \mathrm{ft}\left(\mathrm{ft}^{2}\right)$ & 0.1 \\
\hline
\end{tabular}

Note. Adapted from "Clarifying landscape standards, including Seattle green factor (DPD Director's Rule 10-2011)", by City of Seattle Department of Planning \& Development, 2011. Retrieved from https://www.seattle.gov/Documents/Departments/UrbanForestryCommission/ 2013/2013docs/DR2011_10.pdf

with other biotope area indices, a relatively high weight is given to green spaces created on artificial grounds and the share of three-dimensional greening on the surface of buildings is increased. In addition, systems for assessing single plant species are also established (Table 3).

\section{Comparison Analysis of Biotope Area Indices Used in Korea and Abroad}

\section{Comparison between BAl in Korea and BFF in Berlin}

The Biotope Area Index (BAI) is a tool for quantitatively analyzing changes in ecological values and can be used as an 
environmental planning indicator used to assess ecological soundness. The BAI was developed by benchmarking the BFF used in Berlin, Germany. The index is divided into a total of 13 surface types, and different weights are given to the types depending on their ecological value. The mandatory percentage of green spaces created on natural grounds $(10 \%)$ is applied, and space types include water spaces (permeable, waterproof), green spaces created on artificial grounds (soil depth of less or more than $90 \mathrm{~cm}$ ), green roofs (soil depth of less or more than $20 \mathrm{~cm}$ ), pavements (partial pavement, total permeable pavement, crack permeable pavement), and areas on detention and infiltration facilities. They are classified based on the following functions: evapotranspiration, fine dust absorption, rainwater permeability and storage, soil function, and habitats for animals and plants, and the functions are rated on a scale of 0 to 6 .

Although the assessment criteria are developed based on the area and quantity of vegetation, the type of pavements, spaces for the roots of plants, the possibility of encouraging biodiversity, and the function of evaporating and cooling rainwater absorbed or stored, there have been many failures observed on sites as the originally designed spaces have been built differently considering the cost-effectiveness of the design and also the impact of the results of certification. In particular, these failures have been frequently observed in the types of pavement such as crack permeable pavement and total permeable pavement.

Under the current guidelines, weights are applied only based on the coverage area to cases of covering surfaces only with grass on artificial grounds, and covering them with various plants including trees, shrubs, ground-cover plants and flowering plants. In other words, the results of certification is the same even though more money is invested in covering surfaces with various plants. For this reason, owners choose a type that requires the minimum amount of money, and they have done so on sites. This can be attributed to the fact that BAI weights for each surface type and guidelines were established based on the types of coverage (two-dimensional) only.

When the BAI was first introduced in Korea in 2004, it was developed by benchmarking the BFF used in Berlin. Types such as natural soil greening, green roofs, partial pavement, vegetated walls, and areas on detention and infiltration facilities are similar to those of the BFF, but their weights are slightly different. The type that shows the largest gap is green roofs. Under the BFF criteria, green roofs with the soil depth of both less and more than $20 \mathrm{~cm}$ are given with the same weight (0.7). Under the BAI criteria, however, green roofs with the soil depth of more than $20 \mathrm{~cm}$ is given with the weight of 0.6 , while those with the soil depth of less than $20 \mathrm{~cm}$ is given with the weight of 0.5 . Unlike the BFF, permeable water spaces are given with 1.0, and waterproof water spaces are given with 0.7 . The types of natural soil greening, partial pavement and areas on detention and infiltration facilities are given with the same weights as the BFF.

\section{Comparison between BAl in Korea and GSF in Malmö}

There are 7 same types, and out of them, those that are given with the same weights include natural soil greening, water space (permeable), and crack permeable pavement. Under the GSF criteria, unlike the BAI in Korea, the maximum weight (1.0) is given to water spaces whether they are permeable or waterproof. The weight of green roofs with the soil depth of less than $20 \mathrm{~cm}$ is 0.5 in the BAI, but 0.8 in the GSF. In terms of vegetated walls, their weight in the BAI is 0.4 , but in the GSF a high weight (0.7) is given to them, showing a difference of 0.3 .

There are some distinctive characteristics found in the GSF. First, green roofs are divided into those with the soil depth of more than $80 \mathrm{~cm}$ and those with the soil depth of less than $80 \mathrm{~cm}$, and are given with the weight of 0.8 and 0.6 respectively. Since the depth of soil is directly related to loads acting on buildings, green roofs are divided into those with the soil depth of more or less than $20 \mathrm{~cm}$ in Korea. Second, the GSF stipulates different weights to plant types, which is another major difference between the BAI and the GSF. In Korea, plant types are simply divided into trees, shrubs and climbing plants. 


\section{Comparison between BAl in Korea and SGF in Seattle}

One of the most distinctive characteristics of the SGF is that 7 plants types are further divided into sub-groups such as ground-cover plants, large trees and trees for preservation and that unit areas are also provided. In the case of landscape areas, those with the soil depth of more than $24^{\prime \prime}(60.96 \mathrm{~cm})$ are given with the weight of 0.6 , while those with the soil depth of less than 24 " are given with the minimum weight (0.1). Green roofs are divided into those with the growth medium of more than $4 "$ that are categorized as an intensive type and are given with the weight of 0.7 , and those with the growth medium of more than 2 " but less than $4 "$ that are categorized as an extensive type and are given with the weight of 0.4 . Under the BAI, however, green roofs with the soil depth of 4 " $(10.16 \mathrm{~cm})$ are categorized as an extensive type, while they are categorized as an intensive type under the SGF criteria. In the case of vegetated walls, 0.4 is given to them under the BAI criteria, but 0.7 is given under the SGF criteria, showing a difference of 0.3 . The most important characteristic of the SGF is the application of unit areas based on the length of trees. Bonuses are additionally given to drought-tolerant and native plant species (0.1), and landscape areas where at least 50\% of annual irrigation needs are met (0.2). In addition, public landscapes or urban agricultural landscapes visible to passers-by are given with the incentive of 0.1 .

\section{Comparison between BAI, BFF, GSF and SGF}

The type included all in the four indices is vegetated walls and the GSF used in Malmö and the SGF used in Seattle give the highest weight $(0.7)$ to the type. In particular, the BAI used in Korea provides requirements for installing guide

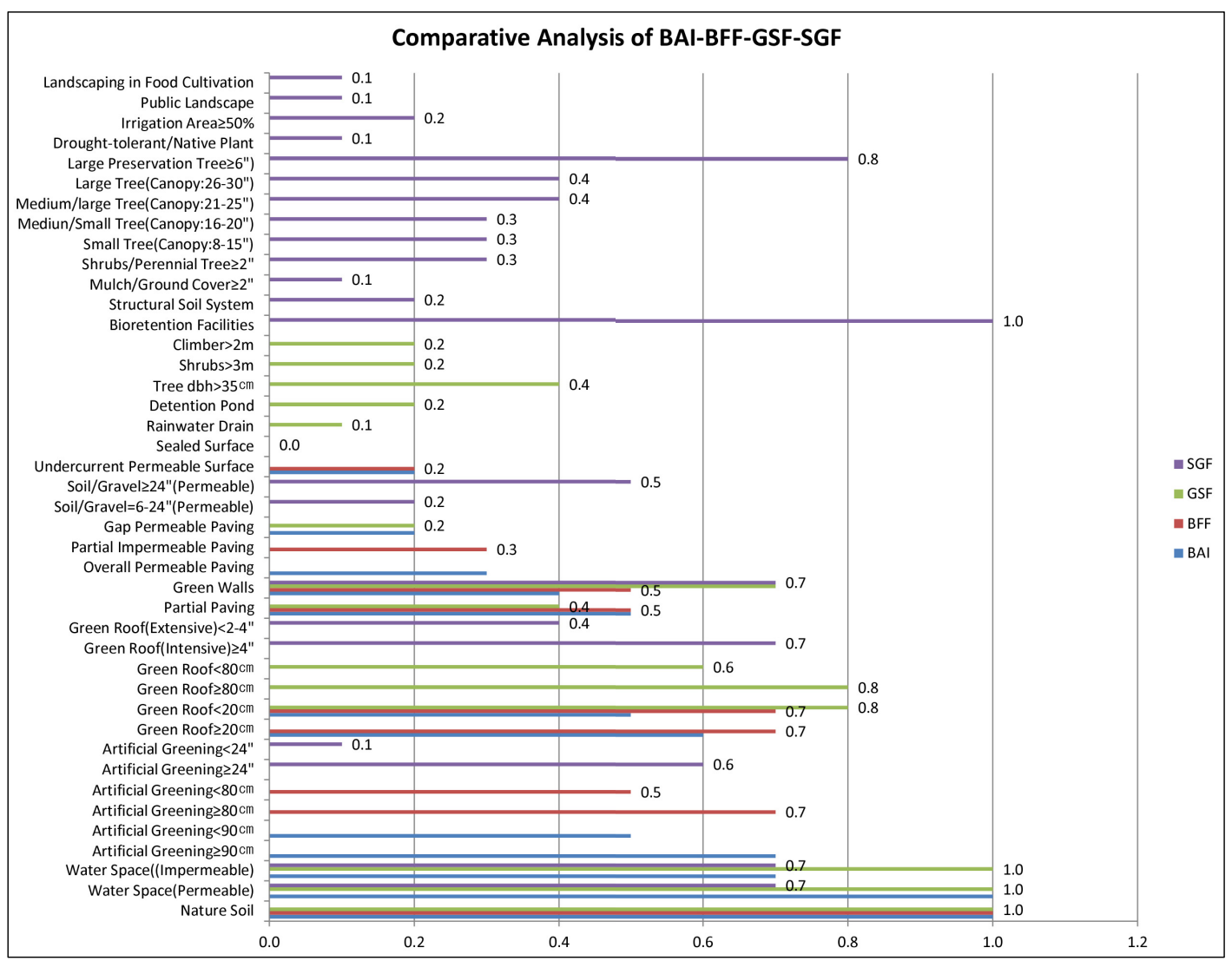

Figure 1. Comparative analysis of BAI-BFF-GSF-SGF. BAI = Biotope Area Ratio (Korea); BFF = Biotopflächenfaktor (Berlin); GSF = Green Space Factor (Malmö); SGF = Seattle Green Factor (Seattle). 
facilities, that is climbing supplementary materials, for vegetated walls only, but there is no guideline on plant species, vegetation density, etc. For this reason, the cost-effectiveness of installing vegetated walls is very low, they are often avoided. Under the BAI, the lowest weight (0.4) among the 4 indices is given to them, showing a difference of 0.3 . Natural

Table 4. Comparative analysis of BAI-BFF-GSF-SGF

\begin{tabular}{|c|c|c|c|c|c|c|c|}
\hline \multicolumn{2}{|l|}{ BAI } & \multicolumn{2}{|l|}{ BFF } & \multicolumn{2}{|l|}{ GSF } & \multicolumn{2}{|l|}{ SGF } \\
\hline Type & Factors & Type & Factors & Type & Factors & Type & Factors \\
\hline Natural soil & 1.0 & Natural soil & 1.0 & Natural soil & 1.0 & & \\
\hline Water space (permeable) & 1.0 & & & \multirow[b]{2}{*}{ Water space } & \multirow[b]{2}{*}{1.0} & \multirow[b]{2}{*}{ Water space } & \multirow[b]{2}{*}{0.7} \\
\hline $\begin{array}{l}\text { Water space } \\
\text { (impermeable) }\end{array}$ & 0.7 & & & & & & \\
\hline $\begin{array}{l}\text { Artificial greening } \\
\geq 90 \mathrm{~cm}\end{array}$ & 0.7 & $\begin{array}{l}\text { Artificial greening } \\
\geq 80 \mathrm{~cm}\end{array}$ & 0.7 & & & Artificial greening > 24" $(60.96 \mathrm{~cm})$ & 0.6 \\
\hline $\begin{array}{l}\text { Artificial greening } \\
<90 \mathrm{~cm}\end{array}$ & 0.5 & $\begin{array}{l}\text { Artificial greening } \\
\quad<80 \mathrm{~cm}\end{array}$ & 0.5 & & & Artificial greening $<24^{\prime \prime}(60.96 \mathrm{~cm})$ & 0.1 \\
\hline \multirow{2}{*}{ Green roof $\geq 20 \mathrm{~cm}$} & \multirow{2}{*}{0.6} & & & Intensive $\quad \geq 80 \mathrm{~cm}$ & 0.8 & \multirow{2}{*}{ Intensive green roof $>4^{\prime \prime}(10.16 \mathrm{~cm})$} & \multirow{2}{*}{0.7} \\
\hline & & Green roof & 0.7 & green roof $<80 \mathrm{~cm}$ & 0.6 & & \\
\hline Green roof $<20 \mathrm{~cm}$ & 0.5 & & & Extensive green roof & 0.8 & Extensive green roof $2-4^{\prime \prime}(5.08-10.16 \mathrm{~cm})$ & 0.4 \\
\hline Partial paving & 0.5 & Partial paving & 0.5 & $\begin{array}{l}\text { Partial impermeable } \\
\text { paving }\end{array}$ & 0.4 & & \\
\hline Green walls & 0.4 & Green walls & 0.5 & Green walls & 0.7 & Green walls & 0.7 \\
\hline \multirow{2}{*}{$\begin{array}{l}\text { Overall permeable } \\
\text { paving }\end{array}$} & \multirow{2}{*}{0.3} & \multirow{2}{*}{$\begin{array}{l}\text { Partial impermeable } \\
\text { paving }\end{array}$} & \multirow{2}{*}{0.3} & & & $\begin{array}{l}\text { Permeable paving 6-24" }(15.24-60.96 \mathrm{~cm} \text { ) } \\
\text { (soil, gravel) }\end{array}$ & 0.2 \\
\hline & & & & & & $\begin{array}{l}\text { Permeable paving > 24" }(60.96 \mathrm{~cm}) \\
\text { (soil, gravel) }\end{array}$ & 0.5 \\
\hline Gap permeable paving & 0.2 & & & Gap permeable paving & 0.2 & & \\
\hline $\begin{array}{l}\text { Concurrent permeable } \\
\text { paving }\end{array}$ & 0.2 & $\begin{array}{l}\text { Concurrent permeable } \\
\text { paving }\end{array}$ & 0.2 & Rainwater drain & 0.1 & & \\
\hline \multirow[t]{14}{*}{ Sealed surface } & 0.0 & Sealed surface & 0.0 & Sealed surface & 0.0 & & \\
\hline & & & & Detention pond & 0.2 & Bioretention facilities & 1.0 \\
\hline & & & & & & Structural soil system & 0.2 \\
\hline & & & & Climber $>2 \mathrm{~m}$ & 0.2 & Mulch/ground cover $\geq 2^{\prime \prime}(5.08 \mathrm{~cm})$ & 0.1 \\
\hline & & & & shrubs & 0.2 & Shrubs/perennials (2" (5.08 cm) 이상) & $\begin{array}{l}0.3\left(18 \mathrm{ft}^{2}\right. \\
\text { per tree })\end{array}$ \\
\hline & & & & & & Small trees (C: 8-15" $(20.32-38.1 \mathrm{~cm}))$ & $\begin{array}{l}0.3\left(75 \mathrm{ft}^{2}\right. \\
\text { per tree })\end{array}$ \\
\hline & & & & & & $\begin{array}{l}\text { Small/medium trees } \\
\left(\mathrm{C}: 16-20^{\prime \prime}(40.64-50.8 \mathrm{~cm})\right)\end{array}$ & $\begin{array}{c}0.3\left(150 \mathrm{ft}^{2}\right. \\
\text { per tree) }\end{array}$ \\
\hline & & & & & & $\begin{array}{c}\text { Medium/large trees } \\
\left.\text { (C: } 21-25^{\prime \prime}(53.34-63.5 \mathrm{~cm})\right)\end{array}$ & $\begin{array}{c}0.4\left(250 \mathrm{ft}^{2}\right. \\
\text { per tree })\end{array}$ \\
\hline & & & & & & Large trees (C: 26-30" (66.04-76.2 cm)) & $\begin{array}{c}0.4\left(350 \mathrm{ft}^{2}\right. \\
\text { per tree })\end{array}$ \\
\hline & & & & Trees DBH $>35 \mathrm{~cm}$ & 0.4 & $\begin{array}{l}\text { Large preservation trees } \\
\left(\mathrm{DBH}>6^{\prime \prime}(15.24 \mathrm{~cm})\right)\end{array}$ & $\begin{array}{l}0.8\left(20 \mathrm{ft}^{2}\right. \\
\text { per tree })\end{array}$ \\
\hline & & & & & & Drought-tolerant/Native plant & 0.1 \\
\hline & & & & & & Irrigation area $>50 \%$ & 0.2 \\
\hline & & & & & & Public landscape & 0.1 \\
\hline & & & & & & Landscaping in food cultivation & 0.1 \\
\hline
\end{tabular}

Note. BAI=Biotope Area Index (Korea); BFF=Biotopflächenfaktor (Berlin); GSF=Green Space Factor (Malmö); SGF=Seattle Green Factor (Seattle); C=Canopy spread; $\mathrm{DBH}=$ Diameter at breast height. 
soil greening, water space (permeable and waterproof), and partial pavement are found in three indices in common. In terms of natural soil greening, the BAI, BFF and GSF, except for the SGF, give the highest weight (1.0) to the type. The BAI and GSF apply 1.0 to permeable water space, while the SGF applies 0.7 to the type. In terms of waterproof water space, the GSF applies 1.0 to the type, while the BAI and SGF apply 0.7 to the type (Fig. 1, Table 4).

Green spaces on artificial grounds and green roofs are similarly used in the four indices, but different weights are applied depending on the soil depth. Under the BAI used in Korea, the highest soil depth (more or less than $90 \mathrm{~cm}$ ) is applied to those created on artificial grounds in apartment complexes, followed by the BFF used in Berlin and the GSF used in Malmö $(80 \mathrm{~cm})$. The SGF used in Seattle divides the soil depth into more or less than $60 \mathrm{~cm}$, showing a difference of up to $30 \mathrm{~cm}$. In the case of green roofs, the GSF used in Malmö applies the highest soil depth $(80 \mathrm{~cm})$, followed by the BAI used in Korea (more than $20 \mathrm{~cm}$ for intensive green roof systems and less than $20 \mathrm{~cm}$ for extensive green roof systems). The SGF used in Seattle recognizes those with the soil depth of more than $10 \mathrm{~cm}$ as an intensive type, applying a high weight (0.7) to them. The index applies the weight of 0.4 to those with the soil depth of more than $5 \mathrm{~cm}$ but less than $10 \mathrm{~cm}$. This can be attributed to the unit area-based criteria for trees and shrubs that are additionally planted on artificial grounds and green roofs.

\section{Conclusions}

The Biotope Area Index (BAI) was first introduced in Seoul in 2004, and, since then, it was partially revised in 2007. As the revised index has continued to be applied since then, many issues have been raised including applying different weights to intensive green roof systems, applying weights to permeable water spaces, applying different weights to grass plants and trees and shrubs, issues raised in the process of installing crack permeable pavements and applying different weights to them. To address these issues, the Seoul Metropolitan Government issued guidelines for the BAI on April, 2016. Under the existing version, surface areas were divided into 12 types, but in the updated guidelines, the number was reduced to eight. One of the most noticeable changes is that vegetated surfaces were categorized as the 8th coverage type, which, in turn, is divided into 3 sub-groups. Trees with the height of less than $4.0 \mathrm{~m}$ are categorized only based on their height, but the area of tall trees with the height of more than $4.0 \mathrm{~m}$ is calculated based on the diameter at breast height (B), the diameter at root collar (R), and the width of crown (W). In addition, to secure an effective soil depth on green roofs, those with the soil depth of more than $40 \mathrm{~cm}$ are not categorized as an intensive green roof system in order to promote plant growth. In the previous version, those with the soil depth of more than $20 \mathrm{~cm}$ were categorized as an intensive green roof system. Major improvements in the revised guidelines include securing the quality of green spaces depending on the height of plants, securing a sufficient soil depth by revising upward the soil depth of green roofs, reflecting the current conditions of permeable and waterproof water spaces in their weights, and revising weights depending on the area of pavements. However, the revised guidelines also failed to reflect concerns on sites in detail. For instance, there are not sufficient criteria for plant species depending on their size. Although the types of surface areas were simplified, there are still issues such as how to verify detailed criteria in an objective way, and the lack of guidelines for technologies associated with the upwardly revised soil depth for intensive green roof systems.

Against this backdrop, this study aimed to examine research trends on the BAI in order to meet the growing needs to meet changing trends and advanced technologies, and to improve the BAI. To do so, the status of operating the BAI in Korea was reviewed, and similar indices used in other countries were compared with the BAI used in Korea. Based on the results, the following conclusions were obtained. The Biotope Area Index (BAI) is an indicator that is widely used on sites in various fields such as apartment houses and facilities used for the purposes of business or education. However, since the 
index has not been timely supplemented or revised, issues have been continuously raised. In this regard, earlier studies on the BAI were reviewed, and criteria used to calculated similar indices in other countries were compared with those for the BAI used in Korea in order to identify issues in the system and to suggest measures to improve it.

First, it is necessary to establish an institutional framework for the BAI as an environmental planning indicator. The BAI has had a significant impact as a preliminary indicator for improvement in urban environments, and is still applied on sites. As an essential element in areas of ecological environment, 10 points are alloted to the index. The local governments of Seoul and Gangdong-gu have made efforts to apply the BAI to their ordinance and to adopt it as a recommendation, and the Ministry of Land, Infrastructure and Transport (MOLIT) also stated that the BAI should be included in the list of items for ecological environments in establishing urban development plans. As guidelines for the BAI are also implemented by laws, it is necessary to strength its role as an indicator for environmental plans and thus to improve the quality of ecological surfaces in all target development projects.

Second, the BAI' potential as a quantitative indicator needs to be realized, and its limitations as a two-dimensional indicator need to be addressed at the same time. Environmental planning indicators should produce the maximum results for the minimum cost in applying technologies on sites. The BAI is an environmental planning tool that can quantitatively assess the soundness of changing values. The BAI was developed by benchmarking the BFF used in Berlin, and gives different weights to surface types depending on their ecological values. However, on sites, failures that do not meet their assessment criteria have been frequently observed especially in the types of pavement such as crack permeable pavement and total permeable pavement. It has been promoted to plant various plant species on green spaces created on artificial grounds, but, due to limitations in guidelines such as applying weights based on the coverage area only, owners choose a type that requires the minimum amount of money. To address these issues, it is recommended to benchmark cases in other countries such as the GSF used in Malmö, Sweden, and the SGF used in Seattle, the United States and to revise the BAI considering situations in Korea.

Third, it is necessary to strengthen the function of indicators for planting trees and shrubs. The necessity of revising weights for the space types and two-dimensional types used in the BAI in Korea has been continuously highlighted. The BFF that the BAI benchmarked has 9 space types and suggest their weights accordingly. However, it also does not have a separate category for landscape planting, but simply mentions it as greening. To address this issue, the index was revised in 2016 to introduce the category of planting and criteria for the height of trees and shrubs and to give additional weights to them. These efforts seem to be positive for a qualitative improvement in green spaces. However, systems to secure the objectivity of the index need to be established, and, to do so, the index and criteria need to be continuously reviewed and supplemented.

Earlier studies have been focused only on space types and their weights. Recently, studies on techniques of calculating the BAI have started to be conducted and measures to address limitations and issues have been developed. However, they are not sufficient considering situations on sites. Therefore, opinions of those who work on sites on problems of and measures to improve the index need to be collected and analyzed in depth. In particular, as the importance of artificial grounds and green roofs has been highlighted in the fields of landscaping, opinions of those who work on sites in various fields, such as designing and building outdoor spaces in apartment complexes and green roofs, handling soil materials, planting and operating facilities, need to be actively collected and analyzed to gradually improve the index. In addition, the quality and performance of new products, and techniques should be reviewed to verify their applicability. 


\section{References}

City of Seattle Department of Planning \& Development. 2011. Clarifying landscape standards, including Seattle green factor (DPD Director's Rule 10-2011). Retrieved from https://www.seattle.gov/Documents/Departments/UrbanForestryCommission/ 2013/2013docs/DR2011_10.pdf

Emilsson, T., J. Persson, and J.E. Mattsson. 2013. A Critical Analysis of the Biotope-Focused Planning Tools: Green Space Factor. Department of Landscape management, Design and Construction, Swedish University of Agricultural Sciences. Department series (ISBN 978-91-87117-59-6) 28:36-38.

Han, Y.H. 2005. Development and application of planning model for decentralized rainwater management in urban housing complexes. J. Korea Plan. Assoc. 40(2):244-246.

Hong, J.S. 2005. A Study on the improvement for the ecological area rate system. J. Korea Plan. Assoc. 2015(11); 2017-1029.

Hong, S.H., B.H. Han, and H.S. Kim. 2012. Survey of the land-cover type pattern in high-rise building. J. Korean Inst. Landsc. Archit. 40(2): 15-23. DOI:10.9715/KILA.2012.40.2.015

Jang, D.H., H.S. Kim, and B.K. Kang. 2010. A basic study on improvement for biotops area ratio through the post evaluation plan for outdoor space of apartment housings. Korea Inst. Ecol. Archit. Environ. J. 10(6):91-96.

Jang, D.H., H.S. Kim, and T.H. Kim. 2012. A study on the supplementation of the biotop area ratio by case study of outdoor environmental planning indicators. Korea Inst. Ecol. Archit. Environ. J. 12(1):3-10.

Kang, E.J. 2009. Condition analysis of biotope area rate in certified environmental-friendly schools. J. Korean Inst. Educ. Facil. 16(2):47-58.

Kang, T.S. and M.W. Lee. 2014. Analysis of the regional effectiveness of urban wall-planting applied by a biotope area ratio: Case of Jung-gu district in Seoul. J. Korean Inst. Landsc. Archit. 42(5):88-100. DOI:10.9715/KILA.2014.42.5.088

Kazmierczak, A. and J. Carter. 2010. Adaptation to Climate Change Using Green and Blue Infrastructure. A Database of Case Studies. Manchester, UK: University of Manchester. Retrieved from http://orca.cf.ac.uk/64906/1/Database_Final_ no_hyperlinks.pdf

Kim, G.S. 2009. A Study on the difference of users' view to biotops area ratio calculation in urban redevelopment of apartment housing. J. Reg. Assoc. Archit. Inst. Korea 11(2):109-116.

Kim, J.H. 2015. A Study on the improvement of G-SEED for revitalizing of its ecological environment. Master's thesis, Kongju National University, Kongju, Korea.

Kim, Y.L. 2012. Influence of urbanization on water circulation and Seoul metropolitan city status. Water J. 97:27-31. Retrieved from http://www.waterjournal.co.kr/news/articleView.html?idxno=15110

Koo, J.H., E.S. Lee, and J.L. Lee. 2007. A Study on the biotop area ration standard for the apartment housing site. Seoul Stud. 8(3):131-142.

Lee, C.W. 2000. A study on the environment capacity assessment of Seoul II (Report 2000-R-11). Seoul, Korea: Seoul Development Institute. Retrieved from http://www.si.re.kr/sites/default/files/2000-r-11_0.pdf

Lee, G.G., S.H. Lee, G.H. Kim, and J.H. Lee. 2011a. Improvement of biotope-area-ratio-indicator and appraisal system applicable to environmental impact assessment projects. J. Korea Soc. Environ. Restor. Technol. 14(5):113-125.

Lee, H.J. 2007. A case study on the application of biotope area in local cities apartment house: the subject of apartments under construction in Yulha new town, Kimhae city. Master's thesis, Gyoengnam National University of Science and Technology, Jinju, Korea.

Lee, J.S. 2010. An analysis of residents' preference for biotope area applied to outdoor space in apartment complex. Master's thesis, Hanyang University, Seoul, Korea.

Lee, S.M., S.M. Lee, and J.H. Meang. 2011b. A Study on comparison between Korea green building certification criteria and LEED by school cases. J. Educ. Environ. Res. 10(2):30-45. DOI:10.7743/kiss.2011.10.2.030

Son, D.P. 2015. The preliminary study for the introduction of biotope area ratio in renewal project area: Focused on 
cost-effectiveness analysis. J. Korea Plan. Assoc. 50(3):109-122. DOI:10.17208/jkpa.2015.04.50.3.109

Song, B.H. 2016. A study on the Improvement of Biotop Area Ratio Indicators: Focused on the Application of Threedimensional Greening Concept. Doctoral dissertation, Kyunghee University, Korea.

Yoon, Y.H., J.H. Kim, and S.D. Kim. 2011. Change of ecological environment sector based on the comparative analysis of revision green building certification standards in apartment housing. Seoul Stud. 12(1):17-31.

Yu, C.H. 2008. A study on the analyzing current biotope area rates and improvement proposal in apartment housing: A case study in Jeonju. Master's thesis, Chonbuk National University, Cheongju, Korea. 